\title{
O Despertencimento Social de Trabalhadores Terceirizados em uma Universidade Pública: Relato de Experiência
}

El despertar social de los trabajadores subcontratados en una Universidad Publica: informe de experiencia

The Social Awakening of Outsourced Workers at a Public University: Experience Report

Faculdade Católica Dom Orione (FACDO), Tocantins/ Brasil

Ana Carolina Carvalho Arruda

ORCID: https://orcid.org/0000-0002-1860-7148

Faculdade Católica Dom Orione (FACDO), Tocantins/ Brasil

Anna Lícya Ferreira Carneiro

ORCID: https://orcid.org/0000-0003-4106-2454

Faculdade Católica Dom Orione (FACDO), Tocantins/ Brasil

Eliane Soares Lima

ORCID: https://orcid.org/0000-0001-6091-1197 Faculdade Católica Dom Orione (FACDO), Tocantins/ Brasil

João Henrique Oliveira Barros

ORCID: https://orcid.org/0000-0003-2552-9755

Faculdade Católica Dom Orione (FACDO), Tocantins/Brasil

Declaração de Direito Autoral

A submissão de originais para este periódico implica na transferência, pelos autores, dos direitos de publicação impressa e digital. Os direitos autorais para os artigos publicados são do autor, com direitos do periódico sobre a primeira publicação. Os autores somente poderão utilizar os mesmos resultados em outras publicações indicando claramente este periódico como o meio da publicação original. Em virtude de sermos um periódico de acesso aberto, permite-se o uso gratuito dos artigos em aplicações educacionais e científicas desde que citada a fonte conforme a licença CC-BY da Creative Commons.

\section{Resumo}

O presente trabalho refere-se a um relato de experiência resultante de um estágio em psicologia organizacional, que decorreu nas dependências de uma Universidade Pública Federal, situada no município de Araguaína/TO/Brasil com trabalhadores terceirizados que atuam na prestação de serviços relacionados à manutenção predial e limpeza em geral. O referido trabalho caracteriza-se como um estudo qualitativo, construído com base nos métodos de observação direta naturalística e entrevistas semiestruturadas, tendo como finalidade a elaboração de estratégias interventivas com foco nos trabalhadores terceirizados a partir de uma compreensão ética, política e social, visando a promoção de saúde e bem-estar dos trabalhadores. No transcorrer do trabalho utilizou-se como base referencial a psicodinâmica do trabalho e a psicologia social do trabalho, a fim de compreender o sofrimento dos trabalhadores dentro de uma lógica capitalista e de sofrimento, construindo um olhar crítico e reflexivo acerca das práxis psicológicas, questionando a desnaturalização da forma como se organiza o trabalho no contexto capitalista. Adiante nos resultados, buscou-se evidenciar e compreender o sofrimento psíquico que os levam a sentimentos de despertencimento social e consequentemente pensar em 
práticas interventivas assertivas para solucionar tais questões, proporcionando a melhoria das atividades laborais, resgatando a dignidade humana na relação trabalho-trabalhador e propiciar qualidade de vida e bem- estar dos sujeitos, sobretudo trabalhando em medidas preventivas.

Palavras-chaves: Precarização do trabalho; Terceirização; Sofrimento e trabalho; Estágio de Psicologia.

\title{
Resumen
}

El presente trabajo se refiere a un informe de experiencia resultante de una pasantía en psicología organizacional, que tuvo lugar en las dependencias de una Universidad Pública Federal, ubicada en la ciudad de Araguaína / TO / Brasil, con trabajadores subcontratados que brindan servicios relacionados con el mantenimiento. Edificio y limpieza en general. Este trabajo se caracteriza por ser un estudio cualitativo, construido sobre la base de métodos naturalistas de observación directa y entrevistas semiestructuradas, con el objetivo de elaborar estrategias de intervención centradas en los trabajadores subcontratados basadas en una comprensión ética, política y social. con el objetivo de promover la salud y el bienestar de los trabajadores. A lo largo del trabajo, la psicodinámica del trabajo y la psicología social del trabajo se utilizaron como base referencial, para comprender el sufrimiento de los trabajadores dentro de una lógica capitalista y de sufrimiento, construyendo una mirada crítica y reflexiva sobre la praxis psicológica, cuestionando La desnaturalización de la forma en que se organiza el trabajo en el contexto capitalista. Antes de los resultados, tratamos de resaltar y comprender el sufrimiento psicológico que los llevó a sentimientos de despertar social y, en consecuencia, pensar en prácticas de intervención asertivas para resolver tales problemas, proporcionando la mejora de las actividades laborales, rescatando la dignidad humana en la relación trabajo-trabajador. Proporcionar calidad de vida y bienestar de los sujetos, especialmente trabajando en medidas preventivas.

Palabras clave: Precariedad del trabajo; Subcontratación; Sufrimiento y trabajo; Pasantía de Psicología.

\begin{abstract}
The present paper refers to an experience report resulting from an internship in organizational psychology that happened on the premises of a Federal Public University, located in the city of Araguaína / TO / Brazil with outsourced workers who provide services related to maintenance building and cleaning in general. This paper is characterized as a qualitative study, built based on naturalistic direct observation methods and semi-structured interviews, aiming at the elaboration of intervention strategies focused on outsourced workers, from an ethical, political and social understanding, aiming at the promotion of workers' health and well-being. Throughout the work, the psychodynamics of work and the social psychology of work were used as a referential basis, in order to understand workers' suffering within a capitalist and suffering logic, constructing a critical and reflective look about psychological praxis, questioning the denaturalization of the way work is organized in the capitalist context. Ahead of the results, sought to highlight and understand the psychological suffering that lead them to feelings of social awakening and consequently to think about assertive intervention practices to solve such issues, providing the improvement of work activities, rescuing human dignity in the work-worker relationship provide quality of life and well-being of the subjects, mainly working on preventive measures.
\end{abstract}

Keywords: Precariousness of Work; Outsourcing; Suffering and Work; Psychology Internship. 


\section{Introdução}

A sociedade e o mercado de trabalho possuem um vasto histórico de transformações econômicas, sociais e tecnológicas. Essas mudanças no mundo do trabalho acabam por provocar um abalo na vida de indivíduos que são impostos a conviver com uma lógica de mercado oscilante, uma situação instável e de constante ameaça, vista como um mal inevitável dos tempos contemporâneos (Dejours, 1999).

Devido a essas mudanças, viu-se a necessidade de aprofundar os estudos acerca da Psicologia Organizacional e do Trabalho (POT), a fim de investigar e compreender como interagem as múltiplas dimensões que caracterizam a vida das pessoas, dos grupos e das organizações. Contribuindo com a elaboração de estratégias e procedimentos que possam promover e preservar a qualidade de vida e o bem-estar dos indivíduos, sem abrir mão da produtividade dentro dos ambientes de trabalho (Zanelli, Borges-Andrade, \& Bastos, 2014).

Esse campo da psicologia, institui-se após a Revolução Industrial ${ }^{1}$ e a alta ampliação do taylorismo ${ }^{2}$, onde priorizava a racionalização do trabalho. De acordo com Mendes (1995) esse processo de racionalizar o trabalho resultou em graves prejuízos à saúde física e mental do trabalhador, pois, devido a grande jornada de trabalho, ritmo acelerado de produção, automação, dentre outros, os trabalhadores começaram a perder o prazer de estar dentro da organização, trazendo a tona uma concepção de trabalho vinculada à adoecimento e sofrimentos.

No que concerne a terceirização, a mesma surge juntamente com a evolução das relações laborais, onde através da globalização

\footnotetext{
${ }^{1}$ A Revolução industrial ocorreu na Europa nos séculos XVIII e XIX, no qual objetivava a substituição do trabalho manual para o uso de máquinas. Essa revolução teve bastante relevância para a construção da sociedade atual e principalmente para o surgimento da revolução tecnológica vivida até os dias atuais (Cavalcante \& Silva, 2011).
}

as organizações buscam por mecanismos como forma de diferencial de mercado, diante disso, encontra-se a terceirização. Em linhas gerais, trata-se de um processo pelo qual uma empresa deixa de realizar uma ou mais atividades executadas por trabalhadores diretamente contratados e as transfere para outra empresa, objetivando a redução dos custos de produção por meio do afastamento de responsabilidades em relação aos encargos e obrigações trabalhistas (Moraes, 2008).

Segundo Cardoso e Goulart (2009) a terceirização é considerada como uma configuração eficaz de trabalho contemporâneo. Entretanto, essa realidade é mais complexa, pois percebe-se que existem diversos problemas que implicam na qualidade dessa atividade. Dentre tais problemas, podemos mencionar questões relacionadas ao despertencimento social desses trabalhadores, pois, de acordo com Alvarenga e Garcia (2007) os trabalhadores terceirizados, em muitas ocasiões, não se sentem pertencentes da equipe efetiva. Isso se dá devido a insegurança presente dentro das estruturas de poder da organização, onde os trabalhadores terceirizados sentem-se vulneráveis no ambiente de trabalho, pois, podem ser dispensados a qualquer momento.

Esse sentimento de insegurança e vulnerabilidade dos trabalhadores terceirizados trata-se da precarização do trabalho, que é elemento central da nova dinâmica do desenvolvimento do capitalismo, criando uma nova condição de vulnerabilidade social (Druck, 2011). Dentro dessas características da precarização do trabalho encontram-se aspectos intrínsecos da terceirização, como: ausência de vínculos trabalhistas, perdas de benefícios, ausência de condições de trabalho dignas, etc. Assim, o trabalhador acaba por se perceber em um ambiente fragilizado enquanto

\footnotetext{
${ }^{2} \mathrm{O}$ Taylorismo é um sistema de organização do trabalho que enfatiza a eficiência operacional das tarefas, no qual se pretende alcançar o máximo de produção e rendimento com o mínimo de tempo e de esforço (Bezerra, 2019).
} 
organização, sentindo-se desamparado de reconhecimento social, adentrando-se nos aspectos da precarização da saúde dos trabalhadores, que é marcada pela fragilização física, mental e subjetiva (Franco, Druck \& Seligmann-Silva, 2010).

O reconhecimento, assim como aborda a psicodinâmica do trabalho, diz respeito a retribuição de maneira simbólica do investimento físico, cognitivo e afetivo do trabalhador para com a organização, sendo por meio disso que se dá a construção da identidade no exercício de determinada atividade, analisando os meios de defesa dos colaboradores diante de situações que lhes causam sofrimento em detrimento ao trabalho, pois este tem uma importância social e psicológica para o indivíduo, e isto se torna de certa forma indivisível, partindo do ponto abordado por Dejours (1987/1992) em que o mesmo afirma que não se separa o trabalhado do ser humano, o sujeito fora e dentro do trabalho.

Dessa maneira, percebe-se que o capitalismo visa por muitas maneiras descartar a humanidade dos trabalhadores, moldando sujeitos alienados, banalizando práticas de competição, de superexploração e de desrespeito à qualidade de vida no trabalho (Hashizume, 2017). Assim, o trabalhador, por ora, precisa desconstruir suas crenças e valores para construir um ideal de trabalhador que se enquadre nas expectativas do mercado, trazendo uma percepção de que todos os conhecimentos acumulados durante a sua trajetória foram considerados inúteis $\mathrm{e}$ descartáveis, separando o trabalhador de sua subjetividade e tornando-o vítima do seu trabalho, ocasionando assim um intenso sofrimento (Dejours, 1999). Dessa forma, é de grande valia fundamentar o questionamento e a desnaturalização da forma como se organiza o trabalho no contexto capitalista assim como nos pressupostos teóricos da psicologia social do trabalho (Bernardo, Sousa, Pinzón \& Souza, 2015).

Nesse contexto, Rodrigues, Alvaro e Rondina (2006) apresenta o sofrimento no trabalho como algo constituído a partir das consequências da insistência do ser humano em manter-se em um ambiente que lhe é adverso. Esse sofrimento que repercute no cenário do trabalho tem origem na história singular de cada pessoa e depende da construção social e psíquica do sujeito.

O sofrimento é algo que já está enraizado na história de cada indivíduo de forma característica. Dejours (1994) comenta que o sofrimento reflete no que ele denomina de "teatro do trabalho", ao entrar em contato com a organização do trabalho. O autor referese ao sofrimento individualizado resultante da construção psíquica e social de cada sujeito. Tudo isso acaba reverberando no ambiente de trabalho, que seria o seu "teatro", tendo seus "personagens" (chefe, funcionário, colegas), o "enredo" (figura de poder, ordem, julgamentos e princípios), e por fim, o "cenário" (a dúvida, inconstância e o desemprego), fazendo uma correlação com a vida real, pela busca incessante da aprovação, que de certa forma é coletiva, a falta desta leva a um grande sofrimento psíquico.

Dessa maneira, ao compreender que determinadas atitudes e situações que ocorrem dentro das organizações estão causando rotineiramente sofrimento nos trabalhadores, cabe-se questionar-se sobre as causas e facilitadores que reforçam esses problemas. Assim, o papel do psicólogo dentro dos ambientes organizacionais é de suma importância. De acordo com Spector (2012), uma das principais práticas do psicólogo organizacional é a análise das atitudes dos trabalhadores em relação ao trabalho, bem como sua satisfação diante do mesmo, considerando a subjetividade e saúde dos trabalhadores. É importante pensar-se em um fazer ético e crítico acerca do trabalho da psicologia nesses espaços, objetivando fornecer um local de trabalho que possibilite ao colaborador alcançar suas ações de trabalho, mas também suas metas pessoais e profissionais.

A Psicologia deve criar estratégias que supram tanto as carências das organizações 
tanto quanto a de seus trabalhadores, intervindo para melhorar as condições precárias de trabalho, garantindo assim a construção de espaços e relações do mesmo mais saudáveis e desta forma dando-lhes condições mais dignas de emprego, através do recebimento de tais incentivos. De certa forma o trabalhador se sentindo bem terá uma boa produtividade no trabalho (Orlandini, 2008).

\section{Metodologia}

Este trabalho trata-se de um registro teórico-prático referente a experiência de Estágio Básico em Psicologia Organizacional, realizado nos meses de fevereiro a junho de 2019, em uma Universidade Pública Federal, no câmpus da Escola de Medicina Veterinária e Zootecnia (EMVZ), situada no município de Araguaína-TO.

O câmpus EMVZ, constitui-se em um dos sete campi da universidade federal do estado, compondo uma das quatro unidades de Araguaína, localizado na zona rural do município. O câmpus oferece cursos de graduação em medicina veterinária e zootecnia, e cursos de pós-graduação (mestrado e doutorado). Havendo cerca de 111 funcionários, distribuídos nos cargos de técnicos administrativos e docentes.

O público alvo da atividade foram os trabalhadores de uma empresa terceirizada de assessoria empresarial, que oferece para toda universidade soluções de mão de obra especializada relacionadas às áreas de segurança, portaria, administração, manutenção de equipamentos e predial, limpeza, jardinagem, dentre outros. No câmpus referido, a empresa opera nas demandas de limpeza em geral e manutenção predial, dispondo de 32 trabalhadores atribuídos nas funções de encarregado, jardineiro, auxiliar de serviços gerais e auxiliar de manutenção predial.

O relato de estágio caracteriza-se como um estudo qualitativo, resultante dos métodos da observação direta naturalística, que tem como intuito observar os comportamentos em situações naturais, sem a realização de intervenção por parte do observador, agindo de forma passiva em relação aos fatos aos passos que surgem naturalmente (Shaughnessy, Zechmeister \& Zechmeister, 2012). E entrevistas semiestruturadas para conhecimento do campo e organização do mesmo.

Como pressuposto, o estágio teve como objetivo realizar observações, a fim de elencar demandas, identificar possíveis adversidades que possam produzir sofrimentos psíquicos nos trabalhadores, bem como compreender o papel da psicologia nesses espaços de trabalho e viabilizar a oportunidade de vivenciar e problematizar a realidade, estabelecendo uma correlação entre a teoria e prática. De modo consequente, com base nas demandas levantadas apresentar-se-á hipóteses interventivas com a finalidade de proporcionar a melhoria das atividades laborais, resgatar a dignidade humana na relação do trabalho e trabalhador e propiciar qualidade de vida e bem-estar dos sujeitos observados.

No perpassar do estágio, foram realizadas oito visitas. Nas primeiras visitas, foram feitas entrevistas semiestruturadas com o encarregado e psicólogo da instituição, para obter informações sobre a empresa, quantidade de funcionários, distribuição de funções, horários, dinâmica estrutural, etc. Após a coleta de informações, foi dado seguimento nas observações em campo, em dias e horários alternados com o intuito de ampliar o campo de estudo, e abranger o máximo da rotina dos trabalhadores. Com o foco na proposta de levantamento de demandas que surgirem no decorrer das atividades, dentre as observações que mais evidenciaram e repercutiram o sofrimento psíquico destes sujeitos, foram: as relações dos trabalhadores para com a empresa e instituição contratante; os vínculos dos trabalhadores com os servidores efetivos da instituição; a dinâmica e distribuição das atividades; a comunicação entre os trabalhadores e gestor.

\section{Resultados e Discussão}


Por meio das observações realizadas in loco, fez-se um levantamento de demandas, viabilizando a percepção da possibilidade de estabelecer uma correlação entre a teoria e a prática, assim como o ampliamento de estratégias de intervenções com foco nos trabalhadores terceirizados a partir de uma compreensão ética, política e social. Segundo Zanelli, Borges-Andrade, Bastos (2014) há diversas competências esperadas para o profissional da psicologia neste campo, a partir de elementos como unidades de análise organizacionais, coletivas, individuais, esferas pessoais, competências técnicas, gerenciais, cognitivas, afetivas, soluções de problemas e de inovações, etc. Dessa forma, apresentar-se-á uma série de hipóteses interventivas elencadas a partir da realidade observada, a fim de proporcionar a promoção do bem-estar dos grupos observados e por conseguinte a melhoria das atividades laborais.

Nesse contexto, de acordo com Bernardo, Sousa, Pinzón \& Souza (2015) ao pensar em uma atuação focada nos princípios éticos, políticos e sociais, é de suma importância que o psicólogo compreenda os aspectos mais amplos do contexto em que se encontra, possibilitando um entendimento dos fenômenos sociais em um enfoque histórico e crítico, analisando integralmente as contradições do trabalho dentro das condições dadas por seus processos de produção particulares. Para isso, cabe ao profissional da psicologia, durante sua atuação, refletir acerca do papel profissional nesses ambientes, bem como o foco e a prioridade dessa atuação. Assim, é possível alavancar uma atuação éticapolítica acerca dos papéis da organização e assim construir novas configurações que possam responder aos problemas reais e atuais, contribuindo para um fazer social efetivo. Segundo Prilleltensky (1994), se os psicólogos não se questionam acerca da dimensão éticopolítica de sua atuação, inevitavelmente, acabam trabalhando a favor dos que têm mais poder.

Ao longo do estágio foi possível observar que os trabalhadores terceirizados sentem-se excluídos socialmente dos demais trabalhadores, que são efetivos. Adentrando nas questões acerca do despertencimento social. Isso se dá devido a falta de reconhecimento, pertencimento e invisibilidade, que ganha forma por meio da desvalorização, discriminação social, do sentimento de existir e ser ignorado ou não ser percebido. Conforme exposto por Irber (2016) é comum à categoria profissional de terceirizados de limpeza e conservação de instituições públicas, representando uma violência simbólica, material e opressora, representando uma humilhação social, uma lacuna entre os cegos superiores e os subalternos (Costa, 2008). É importante mencionar que situações características da invisibilidade são fatores geradores de sofrimento para esses trabalhadores e que precisam ser vistos como objeto de análise organizacional.

Outro ponto observado, trata-se da falta de oportunidades de crescimento pessoal e profissional para a equipe de terceirizados, posto que, ao conversar com o Psicólogo Organizacional e do Trabalho da instituição, foi mencionado que não é disponibilizado cursos profissionalizantes e/ou vagas nos vestibulares da instituição dedicada aos trabalhadores da casa. Com isso, é possível pensar em um projeto que contribuiria nesta demanda, onde poderia ser feito uma re-orientação profissional analisando as possibilidades de crescimento educacional e profissional de acordo com o perfil do trabalhador.

Segundo Soares-Lucchiari (1997) esta re-orientação facilitaria durante o processo do trabalhador diante das perspectivas vivenciadas no cotidiano organizacional, pois o principal objetivo desta prática é trabalhar a relação sujeito-trabalho, a vivência no desempenho da profissão, os sentimentos experimentados e as mudanças alcançadas. Dessa maneira, cooperaria no processo do sujeito em suas escolhas.

Foi perceptível também, que a instituição não dispõe de um ambiente de convivência, no qual os trabalhadores, tanto terceirizados quanto efetivos pudessem ter um 
relacionamento mais adjunto e assim construir um ambiente de debates e trocas de experiências, compreendendo que, independente do cargo exercido, o sujeito, a partir de um entendimento histórico-cultural carrega consigo vivências que podem ser compartilhadas, proporcionando trocas de saberes e assim trabalhando com enfoque na promoção de saúde e bem-estar. Compreendendo que o trabalho é produzido por espaços de socialização, de construção de identidades, experiências e significados, possibilitados por práticas cotidianas e interações (Sato, 2003; Sato, Bernardo, \& Oliveira, 2008).

De acordo com Dejours (1987/1992) a partir dos estudos acerca da Psicodinâmica do Trabalho, esses ambientes de trocas de experiências e debates, propicia uma concepção moderna acerca da subjetividade no trabalho, na medida em que tal abordagem oferece um novo olhar para os estudos do mesmo, sugerindo menos competitividade e mais espaços de debates, para que os colaboradores pudessem exprimir seus sentimentos e as demandas que emergem nesse âmbito, tomadas pela maior parte por ações que produzem sofrimento.

Assim, para que esses problemas citados anteriormente sejam sanados é fundamental, inicialmente, uma gestão que organize esses trabalhadores. Gestão de pessoas conforme Chiavenato (1999) se refere às políticas e práticas necessárias para o manejo e condução dos trabalhadores. E, como elencado por ele, as pessoas representam o principal ativo das organizações, desta forma é imprescindível um olhar mais atento a esses trabalhadores. A gestão se dá por meio de atividades como planejamento, desenvolvimento, manutenção e monitoração da força de trabalho dentro das organizações.

A realização de um treinamento de gestão com o encarregado chefe dos trabalhadores da equipe observada durante o estágio é um ponto de suma importância, tendo em vista que se trata da figura de liderança e referência responsável pela organização do grupo de terceirizados. Segundo Brito (2008) um gestor deve unir políticas e práticas como planejamento, manutenção e monitoração da força de trabalho. Diz ainda que as organizações devem desenvolver a capacidade de aprender, em processo de contínua adaptação às demandas atuais e posteriores que possam vir a surgir. É necessária também a capacidade de gerenciar um conjunto de itens como o saber formal, habilidades de saber fazer e atitudes de querer fazer.

Além disso, percebeu-se também por meio das observações a necessidade de apropriar-se de reuniões semanais para que sejam discutidas de forma clara entre o grupo de trabalhadores questões acerca de suas dificuldades e necessidades, a fim de lhes garantir mais interação grupal e autonomia no seu ambiente de trabalho, bem como possibilitar nesses momentos a organização de questões como uma melhor distribuição das atividades realizadas por eles dentro de uma gestão de tempo que se mostrou falha durante as observações, tendo em vista que nota-se os trabalhadores por bastante tempo ociosos.

\section{Considerações Finais}

É possível constatar, diante todo o exposto, que o trabalhador em seu local de trabalho está diante de inúmeras situações que podem vir a lhe causar adoecimento psicológico, uma vez que o sujeito dentro das organizações é visto apenas como um objeto e/ou mercadoria que deve gerar lucros para as mesmas. Isto se dá principalmente com o grupo terceirizado, dado que se trata de um proletariado muito mais vulnerável que os demais, por serem contratos instáveis, havendo sempre um revezamento de empresas, implicando muitas vezes em uma flexibilização que resulta em falta de férias por anos consecutivos e na ausência do $13^{\circ}$ salário. Estas condições, além de estabelecer um cenário de insegurança, massacram os direitos dos trabalhadores conquistados ao longo da história e acarretam inferências na subjetividade do trabalhador. 
Ao se tratar de um trabalho com uma gestão deficiente a situação se agrava ainda mais, pois logo os trabalhadores se tornam ociosos e desmotivados no exercício de um trabalho sem sentido, alienante, tornando-se apenas corpos úteis (Diniz \& Campos, 2017). Diante deste cenário, observou-se que não são respeitadas questões acerca das limitações e subjetividades dos indivíduos trabalhadores, o que influencia diretamente no bem-estar dos mesmos, haja visto que necessitam do emprego que é a fonte de sobrevivência para suas famílias. Mostram-se na maior parte do período cansados e apáticos, com traços de esgotamento e despertencimento social. Segundo Paschoal, Torres e Porto (2010) a visão de bem-estar está relacionada ao sinônimo de felicidade, enfatizando os aspectos positivos da experiência do trabalhador, principalmente no que diz respeito a sua realização e crescimento pessoal, bem como a expressão do seu potencial individual. $\mathrm{O}$ bem-estar deve ser considerado como o funcionamento positivo do indivíduo.

Desse modo, é de suma importância reconhecer que as condições organizacionais ocasionam de forma direta grandes impactos sobre elementos atrelados a subjetividade e o bem-estar do trabalhador. A preocupação em entender estes aspectos corrobora com a realização de intervenções mais assertivas para solucionar tais questões, sobretudo possibilitando o planejamento de medidas preventivas, que é o mais indicado, com foco em evitar a existência desses problemas e não apenas remediá-los. O bem-estar no ambiente organizacional beneficia não apenas os trabalhadores, mas toda a organização, de modo que irá contribuir na motivação e logo no aumento da produtividade, de forma que não coloque em jogo a saúde mental dos trabalhadores.

\section{Referências}

Alvarenga, P. A., \& Garcia, F. C. (2007).

Relações de Poder nos Processos de

Terceirização: Estudo de caso. Anais do IV

Simpósio de Excelência em Gestão e

Tecnologia, Resende, RJ, Brasil.

Recuperado de

https://www.aedb.br/seget/arquivos/artigos

07/1250_Artigo\%20SEGeT.pdf

Bernardo, M. H., Souza, C. C., Pinzón, J. G.,

\& Souza, H. A. (2015). A práxis da

Psicologia Social do Trabalho: reflexões

sobre possibilidades de intervenção. In. M.

C. Coutinho, O. Furtado, \& T. R. Raitz

(Orgs.), Psicologia Social e Trabalho:

perspectivas críticas (pp. 16-39).

Florianópolis: Abrapso Editora.

Recuperado de

https://www.pucminas.br/pos/psicologia/D ocumentosGerais/Publicacoes/psicologiasocial-e-trabalho-perspectivas-criticas.pdf

Bezerra, J. (2019). Taylorismo. Toda Matéria.

Recuperado de

https://www.todamateria.com.br/taylorismo
Brito, L. M. (2008). Gestão de competências, gestão do conhecimento e organizações de aprendizagem: instrumentos de apropriação pelo capital do saber do trabalhador.

Cadernos de Educação, (31), 203-225.doi: 10.15210/CADUC.V0I31.1748

Cardoso, S. U., \& Goulart, I. B. (2009). As relações de trabalho em equipes terceirizadas: um estudo das significações psicossociais para os trabalhadores e para as organizações. Gestão Contemporânea, 6(6), 147-176. Recuperado de http://seer4.fapa.com.br/index.php/arquivo/ article/view/11/7

Cavalcante, Z. V., \& Silva, M. L. S. (2011). A importância da Revolução Industrial no Mundo da Tecnologia. Anais do VII. EPCC - Encontro Internacional de Produção Científica, Maringá, PR, Brasil.

Recuperado de:

https://www.unicesumar.edu.br/epcc2011/wpcontent/uploads/sites/86/2016/07/zedequias _vieira_cavalcante2.pdf 
Chiavenato, I. (1999). Gestão de pessoas: o novo papel dos recursos humanos nas organizações ( $4^{\mathrm{a}}$ ed.) Rio de Janeiro: Campus.

Costa, F.B.M.N. (2008). Retratos biográficos de dois garis: Um estudo de psicologia social a partir de observação participante e entrevistas. São Paulo: USP.

Dejours, C. (1992). A Loucura do trabalho: Estudo de psicopatologia do trabalho. São Paulo: Cortez - Oboré. (Original publicado em 1987).

Dejours, C. (1994). Psicodinâmica do trabalho: contribuições da escola dejouriana à análise da relação prazer, sofrimento trabalho. São Paulo: Atlas.

Dejours, C. (1999). A banalização da injustiça social. Rio de Janeiro: Fundação Getúlio Vargas.

Diniz, L. F, \& Campos, M. (2017). O trabalhador Contemporâneo e a Subjetividade do Trabalhador. Revista UFG, 17(21), 104-128. doi: 10.5216/revufg.v17i21.51672

Druck, G. (2011). Trabalho, precarização e resistências: novos e velhos desafios?. Caderno CRH, 24(spe1), 37-57. doi: 10.1590/S0103-49792011000400004

Franco, T., Druck, G., \& Seligmann-Silva, E. (2010). As novas relações de trabalho, o desgaste mental do trabalhador e os transtornos mentais no trabalho precarizado. Revista Brasileira de Saúde Ocupacional, 35(122), 229-248. doi: $10.1590 /$ S0303-76572010000200006

Hashizume, C. M. (2017). A precarização do Trabalho e a Subjetividade do Trabalhador. Rev. Psicologia, Diversidade e Saúde, 6 (2), 64-65. doi: 10.17267/23173394rpds.v6i2.1378.

Irber, B. G. (2016). Trabalhadoras terceirizadas de limpeza e conservação da UNB: relatos de violências, invisibilidade e precarização (Monografia). Universidade de Brasília - UNB, Brasília, DF, Brasil. Recuperado de http://bdm.unb.br/handle/10483/13985

Mendes, A. M. B. (1995). Aspectos psicodinâmicos da relação homemtrabalho: as contribuições de C. Dejours.
Psicologia: Ciência e Profissão, 15(1-3), 34-38. doi: 10.1590/S141498931995000100009

Moraes, P. R. S. (2008). Terceirização e Precarização do Trabalho Humano. Rev. TST, 74(4), 48-168. Recuperado de https://hdl.handle.net/20.500.12178/5382

Orlandini, C. C. R. (2008). A importância da psicologia organizacional e do trabalho. Coluna de Psicologia Virtual on-line. Recuperado de http://www.psicologiavirtual.com.br/psicol ogia/principal/noticiaview.asp?id=25281

Paschoal, T., Torres, C. V., \& Porto, J. B. (2010). Felicidade no trabalho: relações com suporte organizacional e suporte social. Revista de Administração Contemporânea, 14(6), 1054-1072. doi: 10.1590/S1415-65552010000700005

Prilleltensky, I. (1994). The morals and politics of psychology: Psychological discourse and the status quo. Albany, NY: State University of New York Press.

Rodrigues P.F., Alvaro A.L.T., \& Rondina R. (2006). Sofrimento no trabalho na visão de Dejours. Revista Científica Eletrônica de Psicologia, (7). Recuperado de http://faef.revista.inf.br/imagens_arquivos/a rquivos_destaque/lh21p1ieajxlwck_2013-510-15-30-2.pdf

Sato, L. (2003). Psicologia, saúde e trabalho: distintas construções dos objetos "trabalho" e "organizações". In Z. A. Trindade, \& A. N. Andrade (Orgs.), Psicologia e saúde: um campo em construção (167-178). São Paulo: Casa do Psicólogo.

Sato, L., Bernardo, M. H., \& Oliveira, F. (2008). Psicologia social do trabalho e cotidiano: a vivência de trabalhadores em diferentes contextos micropolíticos. Psicologia para América Latina, (15) Recuperado de http://pepsic.bvsalud.org/scielo.php?script= sci_arttext\&pid=S1870350X2008000400010\&lng=pt\&tlng=pt

Shaughnessy, J. J., Zechmeister, E. B., \& Zechmeister, J. S. (2012). Metodologia de pesquisa em psicologia. Porto Alegre: AMGH Editora. 
Soares-Lucchiari, D. H. (1997). A reorientação profissional apoio em época de crise. Revista da ABOP, 1(1), 81-88.

Recuperado de

http://pepsic.bvsalud.org/scielo.php?script= sci_arttext\&pid=S1414-

$88891997000100007 \& \operatorname{lng}=$ pt\&tlng=pt.
Spector, P. E. (2012). Psicologia nas

Organizações, $\left(4^{\mathrm{a}} \mathrm{ed}\right)$. São Paulo: Saraiva.

Zanelli, J. C., Borges-Andrade, J. E., \&

Bastos, A. V. (2014). Psicologia, organizações e trabalho no Brasil, (2 $2^{\text {a ed. }) ~}$ Porto Alegre: Artmed.

\section{Dados sobre o autor:}

- Gilson Gomes Coelho: Possui graduação em Psicologia pela Universidade Federal de Mato Grosso do Sul, Campus de Corumbá (2009), mestrado em Psicologia pela Universidade Estadual de Maringá (2015). Doutorando em Psicologia (Psicologia e Sociedade) pela Universidade Estadual Paulista "Júlio de Mesquita Filho", campus de Assis. Atualmente é Professor da Faculdade Católica Dom Orione. Tem experiência na área de Psicologia, com ênfase em Psicologia das Instituições e Organizações. Atuando principalmente nos seguintes temas: Populações Vulneráveis, Questões Psicológicas relacionadas ao Trabalho e as Organizações, Desenvolvimento Comunitário e Relações de Gênero.

- Ana Carolina Carvalho Arruda: Graduanda em Psicologia na Faculdade Católica Dom Orione (FACDO), Tocantins/ Brasil.

- Anna Lícya Ferreira Carneiro: Graduanda em Psicologia na Faculdade Católica Dom Orione (FACDO), Tocantins/ Brasil.

- Eliane Soares Lima: Graduanda em Psicologia na Faculdade Católica Dom Orione (FACDO), Tocantins/ Brasil.

- João Henrique Oliveira Barros: Graduando em Psicologia na Faculdade Católica Dom Orione (FACDO), Tocantins/ Brasil. 